\title{
The narrative review of chronic obstructive pulmonary disease management in Turkey: medical treatment, pulmonary rehabilitation and endobronchial volume reduction
}

\author{
Ipek Candemir^ \\ Ataturk Chest Disease and Chest Surgery Education and Research Hospital, Ankara, Turkey \\ Correspondence to: Ipek Candemir, MD. Ataturk Chest Disease and Chest Surgery Education and Research Hospital, Ankara, Turkey. \\ Email: ipekcayli@yahoo.com.
}

\begin{abstract}
Chronic obstructive pulmonary disease (COPD) is one of the most common chronic diseases. In Turkey, the prevalence of COPD has been shown at rates of $9.1 \%$ to $19.1 \%$, and COPD was found to be the third leading cause of mortality and eighth leading cause of disability. In several national multicentral studies, a high rate of non-adherence to pharmacologic treatment according to GOLD was found to be high, and the most commonly prescribed treatment was the triple regimen. The most important non-pharmacologic treatment of COPD is pulmonary rehabilitation (PR), which is also highly recommended in Turkey, but it is also underutilized, like in other countries. Awareness of healthcare professionals and patients should increase in Turkey. The recommendations in content and modality of programs are similar to international guidelines. Another non-pharmacologic treatment is endobronchial volume reduction (EBVR). Although there is limited number of studies about EBVR, in national reports, the importance of patient selection, method, close follow-up after intervention, and applications in experienced centers are emphasized to decrease the economic burden of this expensive treatment. There is still great need for further randomized studies about pharmacologic and non-pharmacologic treatment and additionally, a close collaboration between healthcare professionals, physicians, professional societies of pulmonology, planners of reimbursement system, patients, patient advocacy groups and the general public should be established.
\end{abstract}

Keywords: Pharmacologic treatment; pulmonary rehabilitation; endobronchial volume reduction

Submitted Jun 23, 2020. Accepted for publication Apr 25, 2021.

doi: $10.21037 /$ jtd-20-2271

View this article at: https://dx.doi.org/10.21037/jtd-20-2271

\section{Introduction}

Chronic obstructive pulmonary disease (COPD) is a common, preventable, and treatable airway disease with persistent and progressive respiratory symptoms and air flow limitations. Risk factors for COPD are smoking, outdoor, indoor and occupational air pollution, and aging of the world's population $(1,2)$. In a subgroup analysis of the ECLIPSE study (Evaluation of COPD Longitudinally to Identify Predictive Surrogate Endpoints), the rate of current smokers was found to range from $25 \%$ to $42 \%$ (3).
As expected, the prevalence of the number of current smokers was higher in patients with COPD than healthy subjects in previous international studies $(4,5)$. The Global Adult Tobacco Survey in Turkey conducted in 2012 showed that the total prevalence of current smoking was $27.1 \%$, and $41.5 \%$ in men and $13.1 \%$ in women (6). In a study published in 2018 , the rate of current smokers in patients with COPD was $49 \%$ (50\% among males and $33.3 \%$ among females) in the Eastern Black Sea region of Turkey (7). The rate was similar to previous

\footnotetext{
$\wedge$ ORCID: 0000-0002-9877-3516.
} 
national studies $(8,9)$. In a recent multicenter study from Turkey, it was found that $56.3 \%$ of 776 patients with newly diagnosed COPD were current smokers, $38.1 \%$ of whom were ex-smokers and $7.2 \%$ had history of biomass exposure (10). Biomass such as organic fuels usually cause indoor air pollution in rural areas of Turkey. In a study that was conducted in women from rural and urban areas of Turkey, women living in rural areas with exposure to biomass fumes were more likely to be diagnosed as having COPD than urban women $(12.4 \%$ vs. $3.9 \%)$, in spite of the prevalence of smoking being higher in the urban group (11). Another important risk factor is air pollution. A strong association has been shown between ambient levels of particulate matter (PM 2.5/10) and the prevalence of COPD $(12,13)$. According to measurements performed in 2019, air pollution level was over $20 \mu \mathrm{g} / \mathrm{m}^{3} \mathrm{PM}_{10}$ in $98 \%$ of Turkey which was recommended over the upper limit according to World Health Organisation (14).

Prevalence, morbidity, and mortality of COPD vary across countries. The estimated number of patients with COPD was 384 million in 2010, and the estimated global prevalence of post-bronchodilator COPD was reported as $12.16 \%$ (10.91-13.40\%) (15). Similarly, in studies conducted in Turkey, prevalence of COPD has been shown to range from $9.1 \%$ to $19.1 \%$ in subjects who were aged over 40 years (16-18). Additionally, mortality rates have been found to be high worldwide, but vary among countries. Since 2016, COPD has been the third leading cause of death worldwide, with an estimated 3 million deaths (5.3\% of all deaths) (19). Similarly, according to the Turkish national disease burden report, it was shown that COPD was the third leading cause of mortality and eighth leading cause of disability, which causes a great national burden (20).

Since COPD is a preventable, treatable, frequent and important disease, it is important to reduce the risk factors and establish optimal management for these patients. The Global Initiative for Chronic Obstructive Lung Disease (GOLD) documents, which are reported in most literature, and are accepted globally, have been revised regularly. In Turkey, the updates and recommendations of GOLD are followed and discussed. In this review, it is aimed to present national recommendations and studies about pharmacologic treatment according to GOLD document and non-pharmacologic treatment consisting of pulmonary rehabilitation (PR) and endobronchial volume reduction in Turkey.

The search engines including PubMed, Science
Direct, and Google Scholar were used for search terms included 'Turkey' AND 'COPD' OR 'Chronic obstructive pulmonary disease' AND 'pharmacologic treatment' OR 'medical treatment' OR 'pulmonary rehabilitation' OR 'endobronchial valve and coil implantation' OR 'endobronchial volume reduction' in English and Turkish. The guidelines, expert reports, review of the Turkish chest physician societies, studies were investigated.

We present the following article in accordance with the Narrative Review Reporting Checklist (available at http:// dx.doi.org/10.21037/jtd-20-2271).

\section{Pharmacologic treatment in Turkey}

The target of COPD management is to decrease symptoms, disease severity, the number of exacerbations, and improve exercise capacity and health status in order to decrease the social and economic burden of the disease according to worldwide guidelines $(1,21)$. In national reports, it was mentioned that pharmacotherapy should be arranged according to the risk of exacerbation, adverse effects of bronchodilators, patent selection, comorbidities, ability of using inhaler devices, and the cost of medications $(22,23)$. There are several international studies including Turkish researchers, and national studies regarding COPD treatment. A multi-center, cross-sectional, observational study including 719 patients with COPD (2.2\% stage I, $33.1 \%$ stage II, $48.1 \%$ stage III, and $16.6 \%$ stage IV according to GOLD 2010) showed that the most commonly prescribed medication was longacting muscarinic antagonists+ long-acting beta-agonists + inhaled corticosteroids (LAMA + LABA + ICS) with a rate of $43.4 \%$. The rate of using treatment containing ICS was $89 \%$. The authors suggested that the reasons for the preference of triple-treatment were inadequate time with patients in outpatient clinics, concerns about symptom and exacerbation control, reimbursement of all bronchodilators in Turkey in 2010. It was concluded that new strategies should be developed for the treatment of COPD to avoid non-adherence and overtreatment in Turkey (24).

In another multicenter, cross-sectional study from Turkey, 307 patients with COPD were grouped according to spirometric classification and the combined classification of GOLD $2011.7 .5 \%$ of patients were stage I, $62.5 \%$ were stage II, $25.4 \%$ were stage III, and $4.6 \%$ were stage IV. According to GOLD 2011 combined classification of COPD, 23.8\% of patients were in group A, $23.1 \%$ in group B, $13.4 \%$ in group $\mathrm{C}$, and $39.7 \%$ in group D. It was demonstrated that one- 
third of stage I and II patients were classified as group C or D. The most common type of inappropriate treatment regimen was overtreatment. The most common overprescribed medication was ICS in $58 \%$ of patients using LABA + LAMA + ICS. It was suggested that overtreatment of ICS could be due to the high use of ICS/LABA combination products in Turkey. Additionally, it was found that treatment according to the combined classification was more cost effective due to the fact that appropriate treatment in the combined classification was slightly higher than spirometric classification $(97.1 \%$ vs. $93.1 \%)$. The authors suggested that this could have been one of the reasons for developing the new assessment system. The non-adherence to the new classification in both Turkey and other countries was mentioned, and the investigators concluded that the interaction between the guideline authorities and pulmonologists should be improved, and better strategies should be developed in order to increase physician adherence to these guidelines (25).

There are also several studies from Turkey regarding treatment based on only the GOLD combined assessment. In another the multicenter, non-interventional, prospective, reallife observational study from Turkey, 776 newly diagnosed patients were not receiving any medication before the study, and it was found that one-third of them were in group C or D according to GOLD 2011 because $12.6 \%$ of the patients had a history of frequent exacerbation before being diagnosed as having COPD. It was demonstrated that more than $70 \%$ of the patients were overtreated. The most commonly prescribed medication was LABA+LAMA+ICS with a rate of $54.9 \%$ (10). In another multi-center cross-sectional study from Turkey called ALPHABET, 1610 patients with COPD were recruited and it was reported that $41.1 \%$ of the patients with COPD were in group A according to the GOLD 2013. Similar to previous studies, $37.2 \%$ of the patients were in group C and D. Additionally, LABA + LAMA + ICS was the most frequently prescribed regimen with a rate of $62.0 \%$. Overtreatment was found to be in $70 \%$. It was also found that for the assessment of symptoms, the mMRC was used more often $(80.1 \%)$ than CAT $(1.3 \%)$, and for the assessment of risk, the number of exacerbations $(52.0 \%)$ was used more commonly than FEV1 $(18.9 \%)$ in the combined COPD assessment. The high rate of non-adherence and overtreatment were also mentioned, and it was concluded that the selection of symptom or risk assessments could change the categorization of patients significantly (26).

In the 2015 GOLD document, due to the inconsistency between the GOLD management strategies and real life, it was recommended to modify managements according to local needs. A new flow-chart was developed by some Turkish pulmonologists because of the high rate of nonadherence to GOLD in Turkey in 2016. In this flow-chart, the assessment of dyspnea as $\mathrm{mMRC} \geq 2$ was recommended initially, and if answered as yes then patients were put in group B or D; if no, patients were in A or C. Secondly, the assessment of risk (post-bronchodilator FEV1 $<50 \%$ of predicted/2 or more exacerbations/1 or more exacerbations needing hospital admission) was recommended. If all was no, patients were grouped into group $\mathrm{A}$ or $\mathrm{C}$, if there was any yes, into group B or D. Finally, the recommended firstchoice treatment in group A was short-acting muscarinic antagonists (SAMA) or short-acting beta-agonists (SABA), in group B LAMA or LABA, in group C ICS + LABA or LAMA, and in group DICS + LABA and/or LAMA (27).

After the 2017 GOLD criteria were launched, in the view of the Turkish Thoracic Society (TTS) in the Report of the GOLD 2017 Global Strategy for the Diagnosis, Management, and Prevention of COPD, it was mentioned that GOLD 2017 treatment recommendations had some limitations, especially in groups $\mathrm{C}$ and $\mathrm{D}$. The Turkish authors suggested that the recommendations of GOLD were based on studies containing heterogeneous patients, and there was no study that was prospectively designed according to the definition of groups C or D. Additionally, although spirometric stage was removed in GOLD 2017, primary outcome in most clinical trials was change of FEV1. Furthermore, most studies on exacerbation had recruited patients with one or more exacerbations (22). Only in the FLAME study 19\% of the patients have two or more exacerbations. In patients with severe exacerbations, comparable results were shown between the LABA + LAMA and ICS + LABA treatment groups. In this study, it was also found that most exacerbations were seen during the followup period (28). In the TTS report, it was concluded that the evidence levels of the recommendations were low due to these reasons. In Turkey, because ICS are overprescribed (27), the TTS recommended to start pharmacologic therapy with one bronchodilator (LABA or LAMA), and during followup, in the event of the presence of persistent symptoms, the other bronchodilator group might be added. It was also recommended that ICS could be added in the event of two moderate or one severe exacerbation. Otherwise, when the patient had fewer exacerbations, ICS might be removed from the treatment. The need of close follow-up to optimize treatment was mentioned (22).

According to COPD assembly of the Turkish Respiratory Society 2017 report, in group A patients, a short or long- 
acting bronchodilator was recommended; in group $\mathrm{B}$, LABA or LAMA, if persisting symptoms LABA + LAMA; in group C, LAMA, if persisting symptoms LABA + LAMA or ICS+LABA; in group D, LABA + LAMA, if persisting symptoms LABA + LAMA + ICS or ICS + LABA. It was recommended that when there were persisting symptoms despite triple-therapy, ICS might be stopped and theophylline, roflumilast or macrolide could be added (23).

Since September 2019, the LABA + LAMA + ICS triple combination has received reimbursement by the Turkish Institution of Social Insurance in patients who have been treated with ICS and LABA for at least 3 months, but have not received adequate response, have frequent attacks (2 or more attacks per year or 1 or more history of hospitalization) and dyspnea (mMRC 2 and above or CAT score of 10 and above). It remains to be seen as to whether this adjustment will affect overtreatment of the triple combination. Nevertheless, use of ICS is still controversial in Turkey. Additionally, there has been lack of data about adherence to escalation and de-escalation of treatment.

The recommendation for the use of roflumilast and azithromycin in Turkey is similar to GOLD. Since 2014, roflumilast got has received reimbursement by the Turkish Institution of Social Insurance in patients with cough and sputum symptoms lasting at least 3 months and 2 or more exacerbations per year for at least 2 years and FEV1 $\leq 50 \%$ in spite of long-acting bronchodilator and/ or ICS therapy. In a recent study from Turkey, 83 patients with COPD in group $\mathrm{C}$ and $\mathrm{D}$ with chronic bronchitis symptoms using roflumilast were analyzed retrospectively and a significant decrease was found in both COPD exacerbations and hospitalizations when compared with the pre-treatment period (29). Azithromycin is used more commonly in exacerbations than in stable COPD in Turkey. Although the prescription rate of theophylline is not low in Turkey, theophylline is recommended unless long-term bronchodilators are unavailable or unaffordable according to GOLD. The accurate rate of use of these molecules in stable COPD has not been shown in studies.

Overtreatment, due to the over prescribing triple treatment, has been the most important problem in pharmacological treatment at least for 10 years in Turkey, even the Turkish authors, societies adjusted the GOLD recommendations for Turkish chest physicians. The chest physicians should follow national recommendations. Additionally, the further randomized multi-centered studies are needed for determining the rate of prescribing the ICS and triple treatment after the recent revised reimbursement.

\section{Non-pharmacologic treatment: pulmonary rehabilitation in Turkey}

Non-pharmacologic treatment is advised to be complementary to pharmacologic treatment and should be part of the comprehensive management of COPD. After prescribing medications, quitting smoking, vaccinations, adherence to treatments, being physically active or pulmonary rehabilitation (PR) are recommended (1). Similarly, in national reports, adjusting pharmacologic treatment, smoking cessation, comorbidity assessment, vaccinations, physical activity, and $\mathrm{PR}(22,23,27)$ are recommended. PR as a corner stone of integrated care and an evidenced-based effective approach is recommended for patients with COPD. PR has several benefits such as improving exercise capacity, health status, dyspnea, symptoms of anxiety and depression, recovery from exacerbations, number of hospitalizations, and health costs $(1,30,31)$. It has been shown to be the most effective treatment to improve dyspnea, health status, and exercise in tolerance; however, it is still underutilized.

Underutilization is major problem of $\mathrm{PR}$ all around the world. It may be due to limited numbers of PR centers/ units, reimbursement strategies, and awareness of health professionals and patients, because it is based on a country's resources. There are 22 units/centers in Turkey (32), which has 81 cities and a population of $83,154,997$ people (33). Reimbursement types are different around the world. Programs are more likely to be reimbursed in Europe by governments (34), similarly in Turkey. In a study in which the records of patients with COPD who underwent PR were obtained from Turkish Institution of Social Insurance, the rate of the 3.214-18.664 COPD patients who underwent PR was about $0.32-0.59 \%$ per year, $52.0-94.8 \%$ of the programs were prescribed by a chest physician, and $62.9 \%$ of the patients received PR in secondary public hospitals between 2008 and 2016. Although these low rates could be due to the higher number of patients with COPD, the authors suggested that it was due to the low number of PR centers and units, and the low awareness of PR among both health professionals and patients (35). In other studies, it has been shown that the knowledge level of primary healthcare providers on COPD and PR were inadequate (36) and besides healthy subjects, patients with COPD did not have enough information about COPD in Turkey $(37,38)$.

Another important problem is non-adherence to PR 
programs worldwide. In most of these studies, the drop-out rate was $20-30 \%$ (39). In a recent review, those reasons were demonstrated as travel and transport problems, a lack of perceived benefit of $\mathrm{PR}$, being a current smoker, illness, and depression (40). Similarly, a 2-year long study from Turkey showed the rate of drop-out as $22.3 \%$ in patients with chronic respiratory disorders. These patients had decreased exercise capacity and sensation of dyspnea (41). Similarly, in Turkey, the most common reasons for non-adherence of PR were found to be the inability of understanding the efficacy and contents of PR program, lack of motivation, and transportation problems $(41,42)$.

According to recent guidelines, patients with remaining symptoms or limited functional capacity, and frequent exacerbations despite optimal pharmacologic treatment should receive PR (43-47). The same recommendations prevail in Turkey (48). Although smoking is not an exclusion criterion, there are also suggestions about referring patients to PR who have quit smoking (49). In Turkey, smoking is not an exclusion criterion, and there is also no cut-off value for FEV1 or age for referring or attending PR. It was also shown that PR was an effective treatment strategy for patients with COPD regardless of FEV1 values or older age $(50,51)$.

PR program staffing also differs across countries $(34,52,53)$, depending on the program settings and available resources. Conventional PR programs typically include one or more physiotherapists, nurses, a respiratory therapist, a respiratory physician (medical director), and may also include a health psychologist, dietician, occupational therapist, pharmacist, social worker, and other staff $(34,52,53)$. In Turkey, multidisciplinary staff is recommended (48), but most units consist of a minimum staff structure with a physician, physiotherapists, and a nurse. There has been one multidisciplinary center integrated with a homecare unit since 2007 and a chronic respiratory failure service since 2011 . This center consists of a chest physician as a medical director, on-site chest physician, three physiotherapists, a dietitian, psychologist, elderly care technician, and two nurses. In the other $21 \mathrm{PR}$ units, a chest physician is the medical director in 13 units, and physical medicine and rehabilitation physicians are in other units (32).

The structure and the setting of $\mathrm{PR}$ is also different across countries. PR programs can be performed as in inpatient, hospital or community-based outpatient or homebased settings (54-56). The most common is hospitalbased outpatient programs $(43,54)$ similar to Turkey.
Community-based outpatient programs do not exist in Turkey yet. Synchronized video conferencing tele-PR has been performed recently. A home-based model has been performed, supervised home-PR is performed by another center, but unsupervised home-PR is more common. In Turkey, similar to other countries, home-based programs have been found to be effective, but not as effective as outand inpatient supervised programs $(43,54,57)$.

Although there is no international or national recommendation about optimum duration of $\mathrm{PR}$ programs, 8 to 10 weeks of PR has been shown to improve dyspnea, fatigue, anxiety and/or depression, physical capacity, and quality of life in patients with COPD (58-61). The most of the PR programs in Turkey last 6-8 week. It is recommended that the duration of individualized programs should be based on achieving goals and patientcentered outcomes according to assessments (48). In a recent review from Turkey, the initial examination was recommended to include medical history, smoking habit, symptoms, medications, comorbidities, routine laboratory blood tests, chest X-ray, electro and echocardiography, pulmonary function tests, arterial blood gas analysis; a physical examination comprising assessment of exercise capacity, nutritional evaluation, assessment of life quality, psychosocial status (anxiety, depression), daily living activities, occupational performance, motivation level, need for social support, need for devices (oxygen treatment, noninvasive mechanical ventilation, walker, wheelchair); and determination of transportation problems, social support, and financial resources (48). After initial assessments, comprehensive individual programs should be structured.

Exercise training is main components of PR. International recommendations about exercise training are similar to Turkey $(48,62-67)$ in order to increase exercise capacity, muscle strength, and endurance, which was found to be related with 8-year mortality in patients with COPD in a study from Turkey (68). Like lower limb exercise training, upper limb exercise training is also important. In studies from Turkey, upper limb strength, which was found to correlate with exercise capacity, quality of life, and dyspnea in patients with COPD (69), and upper limb strength training was shown to improve quality of life and occupational performance in patients with COPD (70). Additionally, patients with severe dyspnea and those who are unable to train at target intensity, neuromuscular electrical stimulation (NMES) can be performed. However, NMES was not found as effective as conventional PR in exercise capacity, but similar improvements in dyspnea, quality of 
life and anxiety, and depression scores were observed (71). In another study from Turkey, similar gains in exercise capacity were found in patients with COPD (72). In patients with COPD, inspiratory muscle weakness may also exist like peripheral muscle weakness. Inspiratory muscle training (IMT) is recommended in these patients according to national and international recommendations. In a recent review from Turkey, IMT is recommended in patients with inspiratory muscle weakness [maximal inspiratory pressure (PImax) $\leq 60 \mathrm{cmH}_{2} \mathrm{O}$ ] with initial intensity with $30 \%$ of PImax and to increase the intensity gradually (48). It was shown that IMT performed with exercise training provided more benefit on inspiratory muscle strength and endurance, and exercise capacity (73).

Other important components of multidisciplinary PR are psychological and nutritional status, body composition assessment, and support if needed, and education of patients and care givers. In national and international studies, more gains in body weight were found after nutritional supplementation as a component of multidisciplinary PR, than with nutritional support alone (74-77).

As it is recommended in Turkey, education of patients and their families, and care givers should be part of the PR program. Patient education should be planned in accordance with the patient's previous experiences, education level, beliefs, attitudes, education, and social and cultural level. Simple booklets, brochures, videotapes, and real applications are used for educational purposes. The training can be performed in small groups or individually according to the needs of the patients, the content of the rehabilitation program, location, and resources (67). In a recent study from Turkey, it was shown that self-management training improved the quality of life and reduced the symptoms of depression and anxiety in patients with COPD (78).

Immediately after multidisciplinary comprehensive PR programs, an assessment of efficacy is recommended (48). Due to the decreasing benefits of PR in time, follow-up programs or maintenance strategies should be structured; however, no recommended maintenance program has been identified in Turkey or other countries yet.

The most important problem is limited number of $\mathrm{PR}$ center/units. It is probably due to the low demand associated with the decreased awareness of chest physicians, healthcare providers, patients, payers. The professional societies should be encouraged to participate in education in after mentioned groups. Health policies that will ensure equity in health care should be developed about PR in patients with chronic respiratory disease. An increase in funding and resources for PR is essential. The resources should be provided for the establishment of PR units in hospitals in all over the country. The further randomized studies on long-term benefits, cost effectiveness and mortality are needed and the reimbursement should also be revised.

\section{Non-pharmacologic treatment: endobronchial volume reduction in Turkey}

Another non-pharmacologic treatment for emphysema is endobronchial bronchoscopic volume reduction. Endobronchial valve replacement and coil implantation are the main bronchoscopic interventions. In selected cases, this treatment reduces end-expiratory lung volume and improves exercise capacity, lung function, and health status after 6-12 months (1). The most common complications are pneumothorax, pneumonia, hemoptysis, and exacerbation of COPD (1). Similarly, in a singlecenter study from Turkey, significant improvement was shown in pulmonary functions and quality of life in selected patients with advanced emphysema after endobronchial coil implantation who had lower morbidity and mortality than with lung volume reduction surgery after intervention (79). In a recent study from Turkey, the data from patients who underwent endobronchial valve or coil placement were analyzed. It was found that the presence of more than one comorbidity in patients who underwent coil treatment was related to mortality. The mortality rate was higher $(37.5 \%$ vs. $10.5 \%$ ) in patients with coils than in those with valves in the presence of multiple comorbidities, but it was not found to be statistically significant. Authors concluded that in patients with severe emphysema with more than one comorbidity, valves were likely to be a better choice than coils (80).

In another single center study from Turkey, authors compared the complications and outcomes such as pulmonary functional tests and exercise capacity in $60 \mathrm{COPD}$ patients. They found similar outcomes and no mortality was observed following neither of interventions. Pneumothorax was the most prevalent complication [3 patients $(9.7 \%)$ ] followed by cardiac arrhythmia in 2 patients $(6.5 \%)$ after endobronchial valve placement while complications after coil implantations were pneumonia in 3 patients (10.3\%), COPD exacerbation in 2 patients $(6.9 \%)$ and pneumothorax in one patient (3.4\%). Hypernatremia and arrhythmia have been not reported previously in national literature. As the authors mentioned, it could be due to the small number of patient 
groups, underlying comorbidities and the experience of the team performing the procedure (81). In another singlecenter study, endobronchial valve placement was performed in 15 patients. Early complications were observed in five patients $(33.3 \%)$ during the 3 -month follow-up period after the EBV treatment (three chronic obstructive pulmonary disease exacerbation, one pneumothorax, and one pneumonia) (82).

In recommendations from national society consensus reports, it is declared that patient selection criteria should be evaluated before each procedure and PR should be planned before and after the procedure. Appropriate patient and method selection should be made by the decision of the multidisciplinary council (pulmonologist, radiologist, pulmonary rehabilitation specialist, thoracic surgeon, and if possible, a nuclear medicine specialist) (83).

Since September 2019, endobronchial volume reduction treatment has been reimbursed under the directives of Ministry of Health which required a report from a medical board including chest disease and/or thoracic surgery specialists in tertiary hospitals, for patients with documented advanced stage COPD completing a PR program.

Endobronchial therapy has also recently become very popular in Turkey, but the exact utilization figures is not currently known. But still, the number of experienced centers in Turkey is quite limited. On the other hand, this treatment modality is still very expensive and have potentially drastic complications. Therefore, the importance of optimal patient and method selection for endobronchial bronchoscopic volume reduction treatments, close follow-ups, and performing these procedures in selected experienced centers have also been mentioned in national reports in order to reduce the economical burden $(22,84)$. But still, there is need for further studies.

Limitations of this review mainly include limited number of published studies especially about endobronchial volume reduction.

\section{Conclusions}

The Turkish recommendations for pharmacologic treatment of COPD, PR and endobronchial volume reduction are in line with international guidelines. Similar problems and obstacles are also seemingly present in most countries as well as Turkey. The chest physicians should follow national recommendations about COPD treatment, PR and endobronchial volume reduction. The awareness of physicians, patients, stakeholders of reimbursement system is both the most important issue and solution for the increasing the number of patients receiving effective PR, and selection criteria for endobronchial valve replacement and coil implantation should be implemented in detail. There is still great need for further randomized studies about pharmacologic and non-pharmacologic treatment and additionally, a close collaboration between healthcare professionals, physicians, professional societies of pulmonology, planners of reimbursement system, patients, patient advocacy groups and the general public should be established.

\section{Acknowledgments}

Funding: None.

\section{Footnote}

Provenance and Peer Review: This article was commissioned by the Guest Editor (Ki-Suck Jung and Chin Kook Rhee) for the series "current epidemiology and policies of COPD worldwide" published in Journal of Thoracic Disease. The article has undergone external peer review.

Reporting Checklist: The author has completed the Narrative Review Reporting Checklist. Available at https://dx.doi. org/10.21037/jtd-20-2271

Conflicts of Interest: The author has completed the ICMJE uniform disclosure form (available at https:// dx.doi.org/10.21037/jtd-20-2271). The series "current epidemiology and policies of COPD worldwide" was commissioned by the editorial office without any funding or sponsorship. The author has no other conflicts of interest to declare.

Ethical Statement: The author is accountable for all aspects of the work in ensuring that questions related to the accuracy or integrity of any part of the work are appropriately investigated and resolved.

Open Access Statement: This is an Open Access article distributed in accordance with the Creative Commons Attribution-NonCommercial-NoDerivs 4.0 International License (CC BY-NC-ND 4.0), which permits the noncommercial replication and distribution of the article with the strict proviso that no changes or edits are made and the original work is properly cited (including links to both the 
formal publication through the relevant DOI and the license). See: https://creativecommons.org/licenses/by-nc-nd/4.0/.

\section{References}

1. Global Strategy for the Diagnosis, Management and prevention of Chronic, Obstructive Pulmonary Disease, 2020 Report. Available online: http://goldcopd.org

2. Eisner MD, Anthonisen N, Coultas D, et al. An Official American Thoracic Society Public Policy Statement: Novel Risk Factors and the Global Burden of Chronic Obstructive Pulmonary Disease. Am J Respir Crit Care Med 2010;182:693-718.

3. Rennard SI, Locantore N, Delafont B, et al. Identification of five chronic obstructive pulmonary disease subgroups with different prognoses in the ECLIPSE cohort using cluster analysis. Ann Am Thorac Soc 2015;12:303-12.

4. Shahab L, Jarvis MJ, Britton J, et al. Prevalence, diagnosis and relation to tobacco dependence of chronic obstructive pulmonary disease in a nationally representative population sample. Thorax 2006;61:1043-7.

5. Schauer GL, Wheaton AG, Malarcher AM, et al. Smoking prevalence and cessation characteristics among U.S. adults with and without COPD: findings from the 2011 Behavioral Risk Factor Surveillance System. COPD 2014;11:697-704.

6. Public Health Institution of Turkey Global Adult Tobacco Survey 2012. Available online: http://www.who. int/tobacco/surveillance/survey/gats/report_tur_2012. pdf?ua=1. Published, 2014. Accessed October 31, 2017.

7. Karadogan D, Onal O, Sahin DS, et al. Factors associated with current smoking in COPD patients:A cross-sectional study from the Eastern Black Sea region of Turkey. Tob Induc Dis 2018;16:22.

8. Bülbül Y, Öztuna F, Gülsoy A, et al. Chronic Obstructive Pulmonary Disease in Eastern Black Sea Region: Characteristics of the Disease and the Frequency of Influenza-Pneumococcal Vaccination. Turkiye Klinikleri J Med Sci 2010;30:24-9.

9. Gunen H, Hacievliyagil SS, Kosar F, et al. Factors affecting survival of hospitalised patients with COPD. Eur Respir J 2005;26:234-41.

10. Suerdem M, Gunen H, Akyildiz L, et al. Demographic, Clinical and Management Characteristics of Newly Diagnosed COPD Patients in Turkey: A Real-Life Study. Int J Chron Obstruct Pulmon Dis 2020;15:261-7.

11. Kiraz K, Kart L, Demir R, et al. Chronic pulmonary disease in rural women exposed to biomass fumes. Ottawa:
Clinical and Investigative Medicine; 2003: 243-8.

12. Liu S, Zhou Y, Liu S, et al. Association between exposure to ambient particulate matter and chronic obstructive pulmonary disease: results from a cross-sectional study in China. Thorax 2017;72:788-95.

13. Doiron D, de Hoogh K, Probst-Hensch N, et al. Air pollution, lung function and COPD: results from the population-based UK Biobank study. Eur Respir J 2019;54:1802140.

14. Kara rapor 2020. Hava Kirliliği ve sağlık etkileri. Temiz hava hakkı paltformu. Available online: https://www. temizhavahakki.com/wp-content/uploads/2020/09/KaraRapor-2020-Son27082020.pdf

15. Varmaghani M, Dehghani M, Heidari E, et al. Global prevalence of chronic obstructive pulmonary disease: systematic review and meta-analysis. East Mediterr Health J 2019;25:47-57.

16. Kocabas A, Hancioglu A, Turkyilmaz S, et al. Prevalence of COPD in Adana, Turkey (BOLD-Turkey Study). Proc Am Thorac Soc 2006;3:A543.

17. Gunen H, Hacievliyagil SS, Yetkin O, et al. Prevalence of COPD: first epidemiological study of a large region in Turkey. Eur J Intern Med 2008;19:499-504.

18. Deveci F, Deveci SE, Türkoğlu S, et al. The prevalence of chronic obstructive pulmonary disease in Elazig, Eastern Turkey. Eur J Intern Med 2011;22:172-6.

19. World Health Organization. Projections of Mortality and Causes of Death. Date last accessed: November 11, 2019. Date last updated: October 2018. Available online: www. who.int/healthinfo/global_burden_disease/projections/en/

20. Ministry of Health Turkey, Institute of Public Health [homepage on the Internet]. Chronic diseases and risk factors survey in Turkey; 2013. Available online: http:// sbu.saglik.gov.tr/Ekutuphane/kitaplar/khrfai.pdf. Accessed August 8, 2014.

21. Miravitlles M, Vogelmeier C, Roche N, et al. A review of national guidelines for management of COPD in Europe. Eur Respir J 2016;47:625-37.

22. Köktürk N, Gürgün A, Şen E, et al. The View of the Turkish Thoracic Society on the Report of the GOLD 2017 Global Strategy for the Diagnosis, Management, and Prevention of COPD. Turk Thorac J 2017;18:57-64.

23. Yazar EE, Oztruk C, Calikoglu M, et al. Türkiye solunum araştırmaları derneği, GOLD 2017 değerlendirme raporu ve stabil KOAH'da tanı, değerlendirme ve farmakolojik tedavi önerileri. Available online: http://www.solunum.org. tr/TusadData/Bookcase/910201714150.pdf

24. Sen E, Guclu SZ, Kibar I, et al. Adherence to GOLD 
guideline treatment recommendations among pulmonologists in Turkey. Int J Chron Obstruct Pulmon Dis 2015;10:2657-63.

25. Turan O, Emre JC, Deniz S, et al. Adherence to Current COPD Guidelines in Turkey. Expert Opin Pharmacother 2016;17:153-8.

26. Gunen H, Yilmaz M, Aktas O, et al. Categorization of COPD patients in Turkey via GOLD 2013 strategy document: ALPHABET study. Int J Chron Obstruct Pulmon Dis 2015;10:2485-94.

27. Gunen H, Kilinc O, Polatli M, et al. Modification of the GOLD recommendations for chronic obstructive pulmonary disease to broaden their usage in Turkey. Expert Rev Respir Med 2016;10:625-8.

28. Wedzicha JA, Banerji D, Chapman KR, et al. IndacaterolGlycopyrronium versus Salmeterol-Fluticasone for COPD. N Engl J Med 2016;374:2222-34.

29. Cilli A, Bal H, Gunen H, et al. Efficacy and safety profile of roflumilast in a real-world experience. J Thorac Dis 2019;11:1100-5.

30. Spruit MA, Singh SJ, Garvey C, et al. An official American Thoracic Society/European Respiratory Society statement: key concepts and advances in pulmonary rehabilitation. Am J Respir Crit Care Med 2013;188:e13-64.

31. Özmen İ, Yıldırım E, Öztürk M, et al. Pulmonary Rehabilitation Reduces Emergency Admission and Hospitalization Rates of Patients with Chronic Respiratory Diseases. Turk Thorac J 2018;19:170-5.

32. Turkish thoracic society, Pulmonary rehabilitation an chronic care assembly. Existing PR center / units in hospitals. Available online: https://www.toraks.org.tr/ subNews.aspx? sub $=182$ \&notice $=5552$, updated on 15 th december 2019.

33. Turkish Statistical Institute. Available online: http://www. tuik.gov.tr/PreTablo.do?alt_id=1059, 04th Feburary 2020.

34. Spruit MA, Pitta F, Garvey C, et al. Differences in content and organisational aspects of pulmonary rehabilitation programmes. Eur Respir J 2014;43:1326-37.

35. Özdemir T, Candemir I, Ergün P, et al. Patients with COPD who underwent pulmonary rehabilitation in Turkey: prevalence, distribution, and mortality Turk J Med Sci 2020;50:141-7.

36. Göktalay T, Tuncal AN, Sarı S, et al. Knowledge Level of the Primary Healthcare Providers on Chronic Obstructive Pulmonary Disease and Pulmonary Rehabilitation. Pulm Med 2015;2015:538246.

37. Yıldız F, Bingöl Karakoç G, Ersu Hamutçu R, et al. The evaluation of asthma and COPD awareness in Turkey
(GARD Turkey Project-National Control Program of Chronic Airway Diseases). Tuberk Toraks 2013;61:175-82.

38. Uzel FI, Karadağ P, Önür ST, et al. A Basic Question: Are Patients with Chronic Obstructive Pulmonary Disease Aware of Their Disease? Turk Thorac J 2017;18:114-8.

39. Corhay JL, Dang DN, Van Cauwenberge H, et al. Pulmonary rehabilitation and COPD: providing patients a good environment for optimizing therapy. Int J Chron Obstruct Pulmon Dis 2014;9:27-39.

40. Keating A, Lee A, Holland AE, et al. What prevents people with chronic obstructive pulmonary disease from attending pulmonary rehabilitation? A systematic review. Chron Respir Dis 2011;8:89-99.

41. Candemir I, Kaymaz D, Ergün P. The Reasons for NonAdherence in Pulmonary Rehabilitation Programs. Eurasian J Pulmonol 2017;19:25-9.

42. Sahin H, Naz I, et al. Why are COPD patients unable to complete the outpatient pulmonary rehabilitation program? Chron Respir Dis 2018;15:411-8.

43. Ries AL, Bauldoff GS, Carlin BW, et al. Pulmonary Rehabilitation: Joint ACCP/AACVPR Evidence-Based Clinical Practice Guidelines. Chest 2007;131:4S-42S.

44. Marciniuk DD, Brooks D, Butcher S, et al. Optimizing pulmonary rehabilitation in chronic obstructive pulmonary disease--practical issues: a Canadian Thoracic Society Clinical Practice Guideline. Can Respir J 2010;17:159-68.

45. Vogelmeier CF, Criner GJ, Martinez FJ, et al. Global Strategy for the Diagnosis, Management, and Prevention of Chronic Obstructive Lung Disease 2017 Report: GOLD Executive Summary. Eur Respir J 2017;49:1700214.

46. National institute for Health and Care Excellence (NICE). Chronic obstructive pulmonary disease in adults. 2016. Ref Type: Online Source. Available online: https://www.nice. org.uk/guidance/qs10, Last updated: 04 February 2016

47. Bolton CE, Bevan-Smith EF, Blakey JD, et al. British Thoracic Society guideline on pulmonary rehabilitation in adults. Thorax 2013;68 Suppl 2:ii1-30.

48. Ergun P. Current Concepts in Pulmonary Rehabilitation. Güncel Göğüs Hastalıkları Serisi 2019;7:7-18.

49. Rochester CL. Patient assessment and selection for pulmonary rehabilitation. Respirology 2019;24:844-53.

50. Ergün P, Kaymaz D, Günay E, et al. Comprehensive outpatient pulmonary rehabilitation: Treatment outcomes in early and late stages of chronic obstructive pulmonary disease. Ann Thorac Med 2011;6:70-6.

51. Kaymaz D, Türkoğlu Sn, Ergün P, et al. Comprehensıve multidisciplinary pulmonary rehabilitation is an effective treatment strategy in elderly patients with COPD. Acta 
Medica Mediterranea 2017;33:321.

52. Brooks D, Sottana R, Bell B, et al. Characterization of pulmonary rehabilitation programs in Canada in 2005. Can Respir J 2007;14:87-92.

53. Garvey C, Fullwood MD, Rigler J, et al. Pulmonary rehabilitation exercise prescription in chronic obstructive lung disease: US survey and review of guidelines and clinical practices. J Cardiopulm Rehabil Prev 2013;33:314-22.

54. Nici L, Donner C, Wouters E, et al. American Thoracic Society/European Respiratory Society statement on pulmonary rehabilitation. Am J Respir Crit Care Med 2006;173:1390-413.

55. Clini E, Foglio K, Bianchi L, et al. In-hospital shortterm training program for patients with chronic airway obstruction. Chest 2001;120:1500-5.

56. Maltais F, Bourbeau J, Shapiro S, et al. Effects of homebased pulmonary rehabilitation in patients with chronic obstructive pulmonary disease: a randomized trial. Ann Intern Med 2008;149:869-78.

57. Candemir I, Ergun P, Kaymaz D, et al. Comparison of unsupervised home-based pulmonary rehabilitation versus supervised hospital outpatient pulmonary rehabilitation in patients with chronic obstructive pulmonary disease. Expert Rev Respir Med 2019;13:1195-203.

58. Houben-Wilke S, Augustin IM, Vercoulen JH, et al. COPD stands for complex obstructive pulmonary disease. Eur Respir Rev 2018;27:180027.

59. Houben-Wilke S, Janssen DJA, Franssen FME, et al. Contribution of individual COPD assessment test (CAT) items to CAT total score and effects of pulmonary rehabilitation on CAT scores. Health Qual Life Outcomes 2018;16:205.

60. Janssen DJ, Wilke S, Smid DE, et al. Relationship between pulmonary rehabilitation and care dependency in COPD. Thorax 2016;71:1054-6.

61. Spruit MA, Augustin IM, Vanfleteren LE, et al. Differential response to pulmonary rehabilitation in COPD: multidimensional profiling. Eur Respir J 2015;46:1625-35.

62. Wouters EF, Posthuma R, Koopman M, et al. An update on pulmonary rehabilitation techniques for patients with chronic obstructive pulmonary disease. Expert Rev Respir Med 2020;14:149-61.

63. Garvey C, Bayles MP, Hamm LF, et al. Pulmonary Rehabilitation Exercise Prescription in Chronic Obstructive Pulmonary Disease: Review of Selected Guidelines: an official statement from the American Association of Cardiovascular And Pulmonary
Rehabilitation. J Cardiopulm Rehabil Prev 2016;36:75-83.

64. Spruit MA, Gosselink R, Troosters T, et al. Resistance versus endurance training in patients with COPD and peripheral muscle weakness. Eur Respir J 2002;19:1072-8.

65. O'Shea SD, Taylor NF, Paratz JD, et al. Progressive resistance exercise improves muscle strength and may improve elements of performance of daily activities for people with COPD: a systematic review. Chest 2009;136:1269-83.

66. Erk M. KOAH ve Pulmoner Rehabilitasyon. In: Erk M, Ergun P. editors. Pulmoner Rehabilitasyon. İstanbul, Türkiye: Toraks kitapları, 2009; 117-129.

67. Ergun P, Yildiz O. editors. Pulmoner rehabilitasyon cep kitabı. İstanbul, Türkiye: Toraks kitapları, 2013.

68. Çiftçi F, Şen E, Akkoca Yıldız Ö, et al. Does exercise capacity, dyspnea level, or quality of life actually predict mortality in patients with COPD? 8-year follow-up. Tuberk Toraks 2019;67:83-91.

69. Kaymaz D, Candemir İÇ, Ergün P, et al. Relation between upper-limb muscle strength with exercise capacity, quality of life and dyspnea in patients with severe chronic obstructive pulmonary disease. Clin Respir J 2018;12:1257-63.

70. Calik-Kutukcu E, Arikan H, Saglam M, et al. Arm strength training improves activities of daily living and occupational performance in patients with COPD. Clin Respir J 2017;11:820-32.

71. Tasdemir F, Inal-Ince D, Ergun P, et al. Neuromuscular electrical stimulation as an adjunct to endurance and resistance training during pulmonary rehabilitation in stable chronic obstructive pulmonary disease. Expert Rev Respir Med 2015;9:493-502.

72. Kaymaz D, Ergün P, Demirci E, et al. Comparison of the effects of neuromuscular electrical stimulation and endurance training in patients with severe chronic obstructive pulmonary disease. Tuberk Toraks 2015;63:1-7.

73. Pehlivan E, Mutluay F, Balcı A, et al. The effects of inspiratory muscle training on exercise capacity, dyspnea and respiratory functions in lung transplantation candidates: a randomized controlled trial. Clin Rehabil 2018;32:1328-39.

74. Landbo C, Prescott E, Lange P, et al. Prognostic value of nutritional status in chronic obstructive pulmonary disease. Am J Respir Crit Care Med 1999;160:1856-61.

75. Ferreira IM, Brooks D, White J, et al. Nutritional supplementation for stable chronic obstructive pulmonary disease. Cochrane Database Syst Rev 2012;12:CD000998.

76. Korkmaz C, Demirbas S, Vatansev H, et al. Effects of comprehensive and intensive pulmonary rehabilitation and 
nutritional support on quality of life and functional status in patients with chronic obstructive pulmonary disease. J Int Med Res 2020;48:300060520919567.

77. Gurgun A, Deniz S, Argin M, et al. Effects of nutritional supplementation combined with conventional pulmonary rehabilitation in muscle-wasted chronic obstructive pulmonary disease: a prospective, randomized and controlled study. Respirology 2013;18:495-500.

78. Özdel Öztürk B, Özgen Alpaydın A, Özalevli S, et al. Self-Management Training in Chronic Obstructive Lung Disease Improves Quality of Life. Turk Thorac J 2020;21:266-73.

79. Bostancı K, Bilgi Z, Ömercikoğlu H, et al. Endobronchial coils in treatment of advanced emphysema: A single center experience. Turk Gogus Kalp Damar Cerrahisi Derg 2019;27:57-62.

80. Tanriverdi E, Doğan D, Turan D, et al. The impact of

Cite this article as: Candemir I. The narrative review of chronic obstructive pulmonary disease management in Turkey: medical treatment, pulmonary rehabilitation and endobronchial volume reduction. J Thorac Dis 2021;13(6):39073917. doi: 10.21037/jtd-20-2271 co-existing comorbid diseases on long-term mortality in bronchoscopic lung volume reduction. Med Glas (Zenica) 2020;17:73-8.

81. Dumanli A, Metin B, Gunay E, et al. Endobronchial valve vs coil for lung volume reduction in emphysema: results from a tertiary care centre in Turkey. Ann Saudi Med 2020;40:469-76.

82. Dogan D, Tascı C. Early Complications Of Endobronchial Lung Volume Reduction Treatment With Endobronchial Valves. Gulhane Medical Journal 2020;62:121-5.

83. Özbudak Ö, Dirol H. Amfizemde Bronkoskopik Hacim Azaltıcı Tedaviler. In: Dalar L, Yilmaz A. editors. Tanısal Ve Terapötik Bronkoskopi Uzlaşı Raporu. Ankara: Türkiye Solunum Araştırmaları Derneği, 2017; 241-259.

84. Gülşen A. Bronchoscopic Lung Volume Reduction: A 2018 Review and Update. Turk Thorac J 2018;19:141-9. 